\title{
A ESFINGE, A TEIA E O ENREDO: LETRAMENTO E CAMINHOS DA DEMOCRACIA NO BRASIL
}

\author{
ANNE GREICE SOARES LA REGINA ${ }^{1}$ \\ ORCID: https://orcid.org/0000-0003-2746-0907
}

\begin{abstract}
RESUMO: Este trabalho objetiva analisar as possibilidades do letramento para uma pedagogia cidadã. Parte-se da ideia de Educação como emancipação, associando-a ao contexto da comunicação de massa, a partir das reflexões de Adorno e Horhkeimer, mas sem desprezar a importância da cultura como instrumento de mediação na relação sujeito e mundo. Adotamos a perspectiva interdisciplinar dos Estudos Culturais, mais especificamente os estudos de Richard Hoggart, pela qual entendemos que os consumidores/espectadores - mesmo expostos aos mass media, que tendem a exercer certo controle cultural e social através do uso do discurso competente - não estão inertes, permeáveis, mas em condições de produzir respostas. Nesse sentido, vislumbra-se a centralidade de políticas educacionais que pensem o letramento como processo que engloba habilidade técnica e aspectos cognitivos, inseridos em um contexto social e cultural que envolve estruturas de poder e ideologia, conforme Brian Street.Assim, o letramento, em um programa educacional para a liberdade inspirado pelo pensamento freiriano e na perspectiva da formação cidadã concretizada pela participação e pela inclusão discursiva, afigura-se como uma possibilidade para ampliar a democracia no Brasil.
\end{abstract}

Palavras-chave:Letramento, Discurso, Educação para a cidadania, Indústria cultural, Democracia.

\section{THE SPHINX, THE WEB AND THE PLOT: LITERACY AND PATHS OF DEMOCRACY IN BRAZIL}

\begin{abstract}
The paper analyzes the possibilities of literacy for a civic pedagogy. We rely on the idea of Education as emancipation, in the context of mass communication, based on Adorno's and Horhkeimer's reflections, understanding the importance of culture as an instrument of mediation between the individual and the world. We adopt the interdisciplinary perspective of Cultural Studies, specifically Richard Hoggart's works, through which we consider that consumers / viewers - even when exposed to mass media which exert cultural and social control through the use of competent discourse - are not inert, permeable, but able to respond. In this sense, we see the centrality of educational policies considering literacy as a process that encompasses technical skill and cognitive aspects, inserted in a social and cultural context involving structures of power and ideology, according to Brian Street. Thus, literacy, in an educational program for freedomseems to be a possibility to widen Brazilian democracy, in line with Paulo Freire's thinking and aiming a civic formation implemented by participation and discursive inclusion.
\end{abstract}

\footnotetext{
${ }^{1}$ Universidade Federal do Sul da Bahia, UFSB. Porto Seguro, BA, Brasil. <annelareg@gmail.com> Educação em Revista|Belo Horizonte|v.36|e223735|2020
} 
Keywords:Literacy, Discourse, Education for citizenship, Cultural industry, Democracy.

\section{LA ESFINGE, LA TELA Y LA TRAMA: ALFABETIZACIÓN Y CAMINOS DE LA DEMOCRACIA EM BRASIL}

RESÚMEN:Este trabajo tiene como objetivo analizar las posibilidades de alfabetización para una pedagogía ciudadana. Empieza con la idea de la Educación como emancipación, asociándola al contexto de la comunicación de masas, basada en los trabajos de Adorno y Horhkeimer, pero sin descuidar la importancia de la cultura como instrumento de mediación en la relación entre sujeto y mundo. Adoptamos la perspectiva interdisciplinaria de los estudios culturales, más específicamente los estudios de Richard Hoggart, por lo que entendemos que los consumidores / espectadores, mismo si expuestos a los medios de comunicación, que tienden a ejercer un cierto control cultural y social a través del uso del discurso competente, no están inertes, permeables, pero capaz de producir respuestas. En este sentido, vemos la centralidad de las políticas educativas que piensan que la alfabetización es un proceso que abarca habilidades técnicas y aspectos cognitivos, insertados en un contexto social y cultural que involucra estructuras de poder e ideología, según Brian Street. Así, la alfabetización, en un programa educativo para la libertad inspirado en el pensamiento de Freire y en la perspectiva de la formación ciudadana concretada por la participación y la inclusión discursiva, aparece como una posibilidad para expandir la democracia en Brasil.

Palabras clave: Alfabetización, discurso, educación ciudadana, industria cultural, democracia.

\section{INTRODUÇÃO}

Num contexto de globalização e de comunicação generalizada, propiciadas pela revolução tecnológica e, principalmente, pela rede mundial de computadores - a internet - , o abismo cultural reflete o abismo social e econômico, produzindo níveis cada vez mais elevados de exclusão, com os graves problemas a ela associados, que crescem em proporção geométrica e são resultantes de uma ordem econômica pautada no capital desregulado e que se alimenta da desigualdade crônica. Assim, é urgente que as políticas educacionais brasileiras pensem em formas de resistência e respostas à encruzilhada pós-moderna que parece retomar o mito do enigma proposto pela esfinge de Tebas, lembrada na trilogia sofocliana (SÓFOCLES, 1990), em que o monstro propôs a Édipo o desafio pelo qual, ao não resolver o enigma, o jovem seria devorado, o que causou a conhecida expressão "deciframe ou te devoro".

Tomamos como ponto de partida a reflexão de Adorno e Horhkeimer que, em Dialética do Esclarecimento, de 1947, no ensaio A indústria cultural: o esclarecimento como mistificação das massas (1985a, p.99-138), descrevem a configuração das grandes cidades modernas, seus aparatos arquitetônicos e as rápidas transformações resultantes do progresso técnico, pondo em foco as grandes metrópoles onde surgiram os movimentos operários, sindicatos, profissionais liberais e a pequena burguesia, camadas sociais importantes no processo de constituição da indústria cultural. Os filósofos apresentam esta nova conformação urbana, feita de pequenos apartamentos, que, com sua pseudo-função de afirmar a independência do indivíduo, mais que o libertar, o aprisiona à força do capital.

À época, a cultura de massa dava os seus primeiros passos e já se punha de braços dados com os governos - totalitários ou democráticos - e em sintonia com o capital, produzindo o necessário entretenimento para a classe trabalhadora, criando fantasias, vendendo corpos, desejos e produtos. Diluía-se, aos poucos, a necessidade de os novos meios - cinema, rádio - produzirem arte, tomada, a partir de então, apenas como ideologia que legitimava os produtos destinados a mero consumo. Em oposição à fruição artística, tinha-se, segundo a análise dos filósofos acima citados, um processo puramente negocial - produção, consumo, venda, altos lucros. Aqui não vai ser possível desenvolver uma análise em relação ao importante trabalho de Hannah Arendt intitulado $A$ crise na cultura: sua importância social e política, datado de 1961, que, evidentemente, permanece como referência fundamental sobre este assunto (ARENDT, 1970). 
Os anos de 1950 trouxeram um ingrediente a mais para esse caldo da cultura delineado por Adorno e Horkheimer - a televisão. Tanto assim que os impactos da TV sobre a população e a sua relação com a educação, no caso mais específico da formação de adultos, foram tratados por Adorno em um debate com Helmut Becker e Gera Kadelbach, no capítulo Televisão e formação, da coletânea Educação e emancipação, que reúne textos de conferências e debates de Adorno divulgados através do rádio entre 1959 e 1969. Nesse diálogo, o autor chamou a atenção para o caráter ideológico da televisão, referindo-se às transmissões televisivas nos EUA, que tentavam insinuar no espectador uma falsa consciência, uma dissimulação do real, observando que tais programações afetavam muito mais as questões da vida cotidiana e das relações humanas do que propriamente a política. Segundo Adorno, a TV criava uma pseudo-realidade: ideias e imagens que produziam um mundo paralelo, uma representação, e o resultado era a confusão operada pelo indivíduo entre o real e a sua projeção, com consequente adesão-interação com este novo universo (ADORNO, 1995).

Adotamos, como lastro teórico que sustenta as análises aqui empreendidas para avaliar a problemática relação entre meios de comunicação e leitura, a perspectiva dos Estudos Culturais, abordagem teórica que surge no pós-Segunda Guerra Mundial e, num primeiro momento, vinculada ao marxismo, mas que dele se desvencilha para focalizar transformações sociais que incluíam tanto um retorno da importância do sujeito, quanto a reapreciação da indústria cultural, a difusão de valores neoliberais e o movimento de ampliação do trânsito dos produtos culturais. Nesse sentido, estes teóricos buscavam enfatizar a competência crítica dos consumidores e, ao mesmo tempo, deixavam de considerar unicamente as questões de classe social como fator explicativo das possibilidades de reação aos novos padrões de consumo, interação sociocultural e política, para contemplar também conceitos como gênero, idade e identidade étnicas. Evidentemente, tal perspectiva se pauta por um conceito de cultura antropológico, cuja reflexão incide sobre os grupos sociais, na tentativa de compreender como a cultura pode movimentar ações de questionamentos ou confirmação da ordem vigente (MATTELART, NEVEU, 2004).

Especialmente importante para embasar o nosso percurso é o pensamento de Richard Hoggart, um dos fundadores dos estudos culturais. A partir de estudos sobre os impactos da indústria cultural, mas sob perspectiva diferente da dos filósofos alemães citados, publica em 1957 o famoso The uses of literacy: aspects of working-class life with special reference to publications and entertainments (HOGGART, 1973), traduzido para o francês como La culture du pauvre (A cultura do pobre). A obra detém-se no estudo dos efeitos da cultura de massa, difundida pelos meios de comunicação, sobre as classes trabalhadoras inglesas após a Segunda Guerra Mundial. Hoggart debruça-se sobre uma nova forma de cultura, imposta de cima para baixo, diferente das relações de comunidade e organizada de forma comercial: os meios de comunicação de massa inseridos na lógica capitalista. O teórico inglês analisa um suposto declínio da cultura da classe trabalhadora, em razão da ofensiva da indústria cultural; para Hoggart, a cultura das classes trabalhadoras não é em nada inferior àquela das elites, mas, ao contrário, tem força e riqueza singulares. Dessa forma, os efeitos da indústria cultural neste estrato da população seriam relativos, pois na classe trabalhadora, analisada por Hoggart, havia sujeitos que traziam consigo um complexo arcabouço e não eram "vazios culturais", meros receptáculos das informações propagadas pelos meios de comunicação. Para ele, esta população operária não era passiva nesse processo, mas era capaz de elaborações que conduziam a respostas que, por sua vez, produziam cultura. O trabalho de Hoggart demonstra que há uma tendência de se supervalorizar o influxo da indústria cultural sobre as classes populares e, ao mesmo tempo, opera, também, um deslocamento de perspectiva, pois sua proposta busca analisar estas complexas relações a partir de uma perspectiva que confere especial atenção aos receptores (MATTELART, NEVEU, 2004). É significativa esta leitura de Hoggart do papel da cultura como categoria que pode intermediar as relações sujeito-mundo: sua abordagem é um importante ponto de partida para o desenvolvimento da noção de letramento como proposta de leitura contra-hegemônica, em tempos de globalização cultural. Igualmente interessante, mas adequado a um trabalho de maior fôlego e com abordagem mais ampla, o fundamental estudo de Clifford Geertz (1989), A interpretação das culturas, configura-se como essencial para dotar esta reflexão também de uma perspectiva semiótica, a partir de um empreendimento etnográfico, com vistas à interpretação do fluxo do discurso social e suas estruturas significantes, para aclarar ainda mais a 
problemática relação entre letramento e meios de comunicação, em meio à teia de significados que envolve e emana da experiência humana ${ }^{2}$.

No mesmo passo da experiência de Hoggart na Inglaterra, e guardadas as diferenças e especificidades de um país marcado pelo processo de colonização e por todas as violências inerentes a esta empresa dos primórdios do capitalismo, em meados dos anos 1960, no Brasil, Paulo Freire também conhecia o papel da cultura, aqui identificado como leitura de mundo e vivência de um determinado grupo social, como instrumento capaz de mediar as relações dos sujeitos com o mundo. Assim, o pensador pernambucano empreendeu um grande movimento de educação popular, que, em seus fundamentos, buscou implementar uma democratização do acesso à instrução como condição para a conscientização das massas num país no qual, àquela época, quase metade da população era analfabeta. Foi neste contexto que Freire concebeu a sua pedagogia da liberdade, em consonância com o seu entendimento acerca da emergência política das classes populares. Como era de se esperar, este movimento de educação das massas tinha implicações políticas e sociais, já que concebia, como parte ativa do seu projeto, a participação livre e crítica dos educandos, a partir das suas próprias vivências, no processo de aprendizagem do mundo contido no ato de ler.

O educando não é um sujeito desprovido de conhecimento, não é um vazio cultural, mas é alguém que, de posse da sua experiência de vida e tendo-a como instrumento de base, passa a compreender o mundo em novas perspectivas. Daí a prática do educador ser calcada, desde o início, na busca e no conhecimento de um vocabulário popular, conferindo valor à experiência do educando como ponto de partida no processo de educação. O educador deve trabalhar o aprendizado a partir do mundo do educando, através das palavras que fazem parte do seu cotidiano e que são carregadas de significado para ele, considerando que a educação como liberdade tem como premissa a tomada de consciência da própria realidade do sujeito, de sua condição e de seu lugar na sociedade (FREIRE, 2011).

É importante esclarecer que todo este movimento de educação popular começou em 1962, com um projeto piloto desenvolvido no estado do Rio Grande do Norte e que apresentou resultados muito positivos, o que levou à extensão do programa e da sua proposta de democratização da cultura. Num país de democracia frágil e seletiva, a deposição do governo em março de 1964 encerrou as perspectivas de participação popular nas decisões políticas pelos vinte anos seguintes. Durante esse tempo, o mundo se transformou notavelmente, com o estabelecimento de novas configurações geopolíticas, decorrentes do consenso de Washington e, pouco mais tarde, com o processo de abertura da União Soviética e com os grandes avanços nas tecnologias e nas comunicações. Em âmbito nacional, os anos 1970 e 1980 consolidaram e ampliaram os meios de comunicação de massa, sobretudo da TV, cujo alcance sobre todo o território nacional cresceu de forma considerável, atingindo e interligando os lugares mais remotos do Brasil.

Os anos 1990 testemunharam o início da revolução da internet e da comunicação generalizada, firmando a era da globalização; mas, pouco antes disso, em meados dos anos 1980, a palavra letramento surgiu no cenário educacional brasileiro, não se contrapondo ao sentido de alfabetização, mas como processo que lhe seria complementar. Alfabetizar é tornar alguém capaz de ler e escrever, mas ler e escrever se tornaram instrumentos insuficientes para as novas demandas que surgiam em meados dos anos 1980. Agora se exigia também o uso social desse saber, que define letramento - do inglês literacy(condição de ser letrado) - como condição para o sujeito poder se integrar e participar do novo modo de organização social. A questão do letramento, como necessidade para o desenvolvimento das habilidades de leitura e escrita e condição essencial às práticas sociais e profissionais, surge praticamente no mesmo momento histórico em lugares distantes geográfica, econômica, social e culturalmente. Observa-se, entretanto, que países desenvolvidos e em desenvolvimento perceberam e trataram o problema de forma diferente. Nos primeiros, a importância dada à centralidade do letramento nos processos educacionais resultou em uma abordagem que estabelecia de forma clara a diferenciação entre letramento e alfabetização; nos países em

\footnotetext{
${ }^{2}$ As limitações deste artigo, infelizmente, não comportam a abrangência desta ulterior investida teórica, que será explorada num próximo trabalho.
} 
desenvolvimento, como o Brasil, os conceitos de letramento e alfabetização acabaram se confundindo, o que contribuiu para a não melhoria nos níveis de competência social da leitura e da escrita (SOARES, 2004). O Brasil passou por grandes transformações tecnológicas e informacionais sem conseguir promover a democratização do acesso à educação, adentrando um contexto de sociedade da informação, expressão recorrentemente utilizada para designar a sociedade pós-industrial, na qual se verificam inovações tecnológicas, administrativas e organizacionais que resultam das facilidades (e do barateamento) da informação, propiciadas pelas rápidas transformações na tecnologia e nas telecomunicações. Este é o contexto em que se constatam a velocidade e o alcance da informação, através da comunicação de massa, concretizados por mídias que se atualizam, se aperfeiçoam, se popularizam e aumentam sua cobertura, como é o caso da TV, mas também de novos meios, difusos e de proporções cujos efeitos, ainda não completamente compreendidos, se afiguram como dificuldades para a pesquisa, como é o caso das redes sociais, Youtube, blogs, videoblogs. Estes canais irradiam-se de forma rizomática, desenhando-se como confluências, emaranhados característicos da própria web e destes tempos de enigmas e desafios.

\section{LER O MUNDO, UM DIREITO HUMANO}

Numa realidade em que os indivíduos estão sempre superexpostos às ações midiáticas, resulta crucial a habilidade de interpretar a realidade circundante. Isto se configura como uma interface entre educação e política, no âmbito do letramento, através da análise da leitura do mundo como mecanismo capaz de ressituar o sujeito, ressignificando o mundo ao seu redor, incluindo-o socialmente, e fortalecendo as bases da democracia. Parece importante expressar que se entende por política aquilo que é público, social, da vida coletiva (CICCO, GONZAGA, 2016).

Quando pensamos nos graves problemas de leitura e as suas consequências para a educação no Brasil, devemos atentar para o fato de tal deficiência estar associada, em geral, ao baixo desempenho em outras matérias do conhecimento na educação básica, prejudicando o desenvolvimento do estudante e comprometendo a sua condição de cidadão: isso pode ser conferido tanto no resultado do PISA, no qual vemos que a um baixo coeficiente de leitura correspondem igualmente baixos indicadores de compreensão de matemática e ciências (PISA, 2018), quanto, mais ainda, nos indicadores da prova Brasil disponibilizados pelo INEP e no site Q-Edu (Q-EDU, 2020). Nestes, confere-se como os baixos indicadores de português e matemática nas $5^{a}$ e $9^{a}$ séries estão alinhados, tendo tido uma melhora paralela de 2013 para 2017, mas sempre abaixo ou muito abaixo daquilo que foi estabelecido como o desejável (INEP, s/d). Ainda que nem sempre estas avaliações quantitativas possam ser efetivamente aproveitadas para uma descrição e interpretação qualitativa do fenômeno - nem sempre os dados numéricos retratam inteiramente a situação real -, parece-nos claro que os indicadores do PISA, decrescentes por capacidade de leitura (considerada, portanto, a mais relevante das três habilidades avaliadas), e os da prova Brasil evidenciem a urgência na implementação do conceito e, principalmente, da prática de letramento social e culturalmente contextualizado, em lugar da sua tradicional visão como mera decodificação (ROJO, 2004).

Neste sentido, a prática de leitura e escrita converte-se em aplicação desta técnica ao contexto social e ao mundo do trabalho, propiciando o desenvolvimento de habilidades de interpretação, relação, análise e crítica. Desdobrando e ampliando o conceito de letramento, seria possível compreender um nível mais específico da realidade, aquele que respeita imediatamente ao conhecimento das complexas conjunturas sociais e econômicas, o desafio a que somos chamados a responder no mundo da comunicação generalizada e veloz, aproximado e conectado pelas redes de comunicação, de textos, emaranhados discursivos que, como teias, nos enredam e reclamam respostas rápidas e competentes, para que não sejamos devorados.

Se há conhecimentodo ponto problemático da nossa educação, e inclusive já se tem - pelo menos há cerca de trinta anos - ideias para atacar o problema, o que realmente nos impede de avançar? A resposta necessita de reflexão sobre quais políticas educacionais estão sendo aplicadas ao problema e, nesta perspectiva, que visão de língua se consagrou nos ensinos superiores no Brasil e como ela tem 
contribuído para a formação de profissionais da educação que perpetuam um modelo esgotado de ensino de língua materna, deixando cada vez mais evidentes as suas falhas.

Ao analisar a formação dos professores de português nos cursos de licenciatura em letras, percebe-se o fosso existente entre as diversas teorias ensinadas e a prática pedagógica (OLIVEIRA, 2014). Com isso não se quer diminuir a importância dos conhecimentos teóricos (e gramaticais), pois serão eles que darão a fundamentação para as ações do docente. Assim, tomando por empréstimo as observações de Luciano Amaral Oliveira (OLIVEIRA, 2014), iniciaremos o percurso investigativo pontuando dois aspectos a serem considerados e retrabalhados, para que se possa reformular o ensino de língua materna na educação básica: 1) Com qual conceito de língua se trabalha; 2) Por que se ensina português a brasileiros.

Para responder a essas questões e entender melhor a proposta do letramento, não podemos desprezar as marcas profundas do estruturalismo na visão de língua que ainda domina o ensino básico. Podemos dizer que o estruturalismo de base saussureano e seus desenvolvimentos ao longo do século XX deram a tônica dos cursos de letras no Brasil a partir dos anos 1950 e 1960 , projetando-se para as décadas seguintes e influenciando profundamente gerações de professores de português, através de uma concepção de língua como um sistema que se forma a partir de um conjunto de elementos, cada um deles desempenhando um papel específico na organização e constituição da estrutura como um todo (MENDES, 2012). De acordo com esta visão, a língua é estudada como estrutura abstrata, sem levar em conta o uso, embora a análise de Saussure e dos demais estudiosos estruturalistas que o sucederam, a exemplo de Noam Chomsky, reconheça que a linguagem tem um lado social e outro individual, ligados entre si. No esquema de Saussure, a exclusão do aspecto social, portanto da parte que diz respeito ao uso da língua, vinha atender a uma necessidade de delimitação de campo de estudo e à emergência da constituição da linguística como ciência; dessa forma, a referência não é um problema da linguagem, pois o objeto de estudo são apenas as relações intrassígnicas, dentro, portanto, de um abstrato arcabouço estrutural. A partir deste entendimento, a relação com a realidade fica completamente apartada dos estudos sobre a linguagem, de forma que as implicações acerca das questões relativas ao valor, à análise, à crítica e outras de cunho social são questões extralinguísticas, objeto de filosofia ou da lógica (ARAÚJO, 2004).

Oliveira (2014) responde às formulações por ele propostas, ponto de partida para transformar o ensino de português na educação básica, tornando-o mais produtivo. $O$ estudioso pressupõe que estas mudanças, necessárias e urgentes, passam por uma conscientização de que a abordagem formalista acima descrita - conceito de língua ainda muito trabalhado na formação docente - em prejuízo de uma perspectiva interacionista ou sociointeracionista, que pensa a língua como forma de interação sociocultural, levando-se em conta, portanto, as condições culturais dos sujeitos envolvidos no aprendizado -tem prejudicado muito o ensino de língua materna.Isso pode ser explicado diante do fato de que são valorizadas as estruturas e uma gramática distante da realidade da fala de grande parte da população brasileira, situação que tem contribuído para o desinteresse e a desmotivação dos alunos do ensino básico em relação à língua portuguesa, vista, sob esse prisma, como algo estranho, difícil e inacessível. Tal situação torna o processo de aprendizado desastroso e com êxitos, em termos de domínio da comunicação, bem exíguos, o que resulta em estudantes (e em uma grande parcela da população adulta) com extrema dificuldade para elaborar os seus discursos, para realizar leituras críticas e com pouca competência para estabelecer relações entre textos, porque lhes falta não o conhecimento da língua, mas a capacidade de interação nas diversas situações; falta-lhes o aprendizado do comportamento linguístico adequado às práticas sociais que envolvem o uso do seu idioma. Então, o ensino de português para brasileiros deve objetivar desenvolver no estudante a competência comunicativa, instrumento essencial para a participação, através da leitura do mundo, requisito essencial para uma democracia.

A histórica despolitização de setores populacionais, desde sempre excluídos das decisões em nosso país, situação em que à marginalização social se soma a marginalização educacional, só aumenta o fosso de desigualdades na sociedade brasileira e torna a democracia um sonho sempre mais distante, pois democracia implica participação, que, por sua vez, exige leitura e inserção: caso contrário, serve para a manutenção das oligarquias que historicamente moldaram e estrangularam o Brasil. 
É necessário, portanto, historicizar e contextualizar as condições de participação política no Brasil, esclarecendo que a ampliação do direito ao voto se deu gradativamente no País, primeiro com o fim do voto vinculado à renda, com o advento da República, habilitando ao sufrágio todos os homens alfabetizados e maiores de 21 anos; depois, em 1932, quando se ampliou o direito ao voto também para as mulheres. Para os analfabetos, o direito ao voto veio através da Emenda Constitucional $\mathrm{n}^{\circ}$ 25, de 15 de maio de 1985; e, para os jovens com 16 anos, com a Constituição Federal de 1988 (DANTAS, 2010). Se a ampliação do direito ao voto como estratégia de democratização do processo político buscava torná-lo mais equitativo, uma vez que se criava mais dificuldade para que um candidato pudesse exercer sobre a camada da população votante o seu fascínio pessoal - por certo em razão de uma identidade de classe -, a comunicação de massa e os meios digitais criaram novas dificuldades, pois passaram a exigir uma sempre maior desenvoltura e relativa inserção social do ato de leitura nas novas relações que se estabeleceram entre o sujeito e as novas redes de interlocução. Faltavam às camadas populares o conhecimento da democracia e de um contexto democrático; faltavam, em suma, inclusão social e educacional. Assim, a Constituição Federal de 1988, voltada para a construção de uma sociedade plural, estabelece, já no título I, dos princípios fundamentais, art. $1^{\circ}$, parágrafo único, que "todo poder emana do povo, que o exerce por meio de representantes eleitos ou diretamente, nos termos desta Constituição" (BRASIL, 1988), aliando democracia participativa a mecanismo de participação popular, por meio de instrumentos como referendo, plebiscito e iniciativa popular. Tal abertura, consagrada pela carta magna, tem como lastro uma transformação na teoria do direito, de um modelo monista de inspiração liberal e supostamente científico, que tem o Estado como único centro de poder e único produtor das normas jurídicas, para uma concepção pluralista. O pluralismo é a formulação teórica que pensa o direito a partir de uma perspectiva que engloba as ações de comunidades e a diversidade cultural como importantes para a produção e para a aplicação das leis: trata-se de um direito vivo, que surge no tecido social. Tal passagem teórica vincula-se à constatação de novas formas de exclusão e intensificação das desigualdades resultantes do processo de globalização e da expansão do modelo neoliberal de gestão do Estado. Assim, o direito responde às novas demandas sociais, propondo o debate acerca das imposições, homogeneizações das identidades culturais e da naturalização das relações de poder, mal escondidas sob a face de neutralidade do discurso jurídico, consagradas pela modernidade. Parece ser esta a explicação para a transformação empreendida pela Constituição Federal de 1988, que, fruto do árduo processo de redemocratização do Brasil, rompeu com a histórica tradição individualista das nossas constituições anteriores. A Constituição reflete esta vontade e necessidade de acolhimento a novas formas de legalidade, a novos direitos, no contexto de novas configurações econômicas, sociais e políticas próprias da pós-modernidade que, por acentuarem as desproporções de forças, impostas por uma violenta ordem neoliberal, reclamam uma interpretação do direito mais inclusiva ${ }^{3}$.

Se a cidadania, que se traduz em participação, é ponto essencial da carta magna, na prática as políticas educacionais têm deixado de promover a inserção e a educação política, fatores que efetivariam a vontade constitucional. Percebemos esta negligência tanto pela pouca eficácia do ensino de língua materna, conforme dissemos antes, mormente nos estabelecimentos públicos, cada vez mais precarizados (INEP, s/d), quanto também pela ausência de um projeto para educação cidadã. Esta lacuna decorre de uma educação conteudística (FREITAS, 2002), carente de integração entre os componentes curriculares, que provoca a desmotivação do estudante e uma formação fragmentada que, mais que prepará-lo para conhecer a realidade ao seu redor e relacioná-la com as diversas leituras e conhecimentos, direciona o aluno para responder provas, para alcançar metas que lhe franquearão possibilidades profissionais futuras, desde que se insira na desejável mão de obra qualificada ditada pelo "mercado".

\footnotetext{
${ }^{3}$ Para maior aprofundamento, sugere-se a leitura de L. CARVALHO. Caminhos (e descaminhos) do pluralismo jurídico no Brasil. In: WOLKMER, A.C.; VERAS NETO, F.; LIXA, I. Pluralismo jurídico os novos caminhos da contemporaneidade. São Paulo: Saraiva, 2013; S. DOBROWOSLKI. O pluralismo jurídico na Constituição de 1988. Revista de Informação Legislativa. Brasilia a. $n .28 . \quad$ p.7-16. $1991 . \quad$ Disponível em: < http://www2.senado.leg.br/bdsf/bitstream/handle/id/175806/000451403.pdf?sequence=1> 
O processo de exclusão de grande parte da população dos processos decisórios e políticos do País tem se perpetuado, manifestando-se intimamente vinculado às históricas exclusões sociais e econômicas. Evidentemente, esta ausência está associada tanto à nossa marca colonial, que imprimia um caráter autoritário e exógeno às decisões políticas, afastando, desde sempre, o envolvimento do povo na participação social e política, quanto a históricos problemas de educação e acesso à informação, como desdobramentos do regime colonial. Nessa perspectiva, o problema tem relação direta com os deficits educacionais, para não se falar nos números do analfabetismo, que, segundo dados, indicam que os analfabetos brasileiros em 1890 alcançavam um percentual de 85\% da população, enquanto, em 1920, os iletrados correspondiam a 75\% do todo populacional (SILVA, 2004).

Atualizando um pouco mais esses dados, mencionamos os últimos anos da década de 1960, as décadas de 1970 e 1980 e o projeto de alfabetização em massa encampado pelo MOBRAL Movimento Brasileiro de Alfabetização, fundação de direito público criada em 15 de dezembro de 1967, através da lei no 5.379, com o objetivo de combater o alarmante índice de 39,7\% de analfabetos entre a população maior de 15 anos no Brasil, segundo o censo de 1960. No censo de 1970, esse número era de 33,8\%; e, em 1980, o percentual era de 25,5\% (IBGE, 2000). O MOBRAL tinha uma concepção tecnicista da educação e objetivava a formação de mãodeobra para o trabalho, em completo antagonismo com a ideia de Paulo Freire de educação como liberdade, como agente de inserção integral do sujeito no mundo. Este programa foi extinto em 1985, sem alcançar os resultados esperados, pois objetivava a eliminação total do analfabetismo no Brasil em 1975 (FGV, 2009). Na última década do século XX, o número de analfabetos ainda era bastante significativo, girando em torno de 19,7\% (PINTO et alii, 2000; nesse trabalho, a taxa de analfabetos em 1900 e 1920 corresponde a 65,3 e 65\%, respectivamente). Observação importante e dramática feita por Rosa Virgínia Matos e Silva no início do século XXI dava conta de que:

\footnotetext{
A situação atual mostra que menos de $20 \%$ da população brasileira atingem o $2^{\circ}$ grau de escolaridade e somente $38 \%$ concluem a $1^{\text {a }}$ série do primeiro grau. Admitindo-se como suficientemente letrados - avaliação otimista - os que concluem as quatro séries iniciais de escolarização, permanecemos na década de 1990 com menos de 20\% (SILVA, 2004, p.99).
}

A interrupção do projeto de educação popular de Paulo Freire e o fracasso do MOBRAL são eventos significativos para a história da educação no Brasil e refletem a histórica não popularização da educação, causando como consequência, para uma parcela significativa dos brasileiros, a exclusão das decisões políticas. Nesse sentido, o movimento de democratização em meados da década de 1980 e a Constituição - que validou suas diretrizes, apontando já no art. $6^{\circ}$ a educação como um direito social e, no art. 205, como direito de todos e dever do Estado e da família - não consolidaram no Brasil, por não virem acompanhados da implementação de adequadas políticas educacionais, este direito fundamental, classificado pela Teoria do Direito como de segunda dimensão, de que é titular o ser humano em sua individualidade, e que se funda no princípio da igualdade ${ }^{4}$. Estes direitos despontaram no contexto da industrialização e dos graves conflitos socioeconômicos no fim do século XIX e início do XX e acabaram por produzir uma crise do modelo liberal de estado, fazendo surgir em seu lugar o estado de bem-estar social, que passou a regular as relações entre o capital e o trabalho, estabelecendo os direitos sociais, econômicos e culturais como direitos humanos que se positivam quando garantem, a todos, o trabalho, a saúde e, de forma mais importante para o enfoque do nosso trabalho, a educação, instrumento capaz de oferecer instrução aos sujeitos, fornecendo-lhes o meio adequado para que possam participar do mundo em condições de igualdade. A leitura, assim entendida, afigura-se como um direito humano.

A situação de exclusão educacional pode ser entendida através de outro dado importante, e que certamente se traduz em exclusão política: os baixíssimos índices de alfabetismo no Brasil

${ }^{4}$ Para informações mais aprofundadas sobre o assunto, ver A.C. WOLKMER, J.R.LEITE. 2012. 
atualmente. Estudo realizado em 2017 (Instituto Paulo Montenegro/Ação Educativa, 2018), baseado na escala INAF - indicador de alfabetismo funcional - demonstra as limitações na capacidade de leitura, escrita e matemática constatadas no mundo do trabalho.Observe-se que o estudo analisa o problema a partir da perspectiva do trabalho, com um viés econômico, portanto, mas dá uma dimensão do problema aqui tratado. Segundo as estatísticas divulgadas, apenas 12\% dos brasileiros entre 15 e 64 anos dominam as habilidades de leitura, escrita e matemática em língua portuguesa, estando aptos a elaborar textos de maior complexidade e a opinar sobre o estilo e o posicionamento do autor, a interpretar tabelas e gráficos que envolvam mais de duas variáveis, compreendendo modos de representação de informação quantitativa e a resolver situações que envolvam etapas de planejamento, controle e elaboração que exigem retomada de resultados parciais e o uso de inferências.

Segundo a pesquisa citada, $64 \%$ dos sujeitos inseridos no mundo do trabalho têm níveis de leitura e matemática que vão de analfabetos, num percentual de $8 \%$ (o dobro dos analfabetos que havia em 2015), passando por alfabetizados em nível rudimentar, que compreendem $22 \%$ dos sujeitos investigados, e alfabetizados em nível elementar, que somam $34 \%$ dos casos analisados. Os alfabetizados rudimentares seriam capazes de interpretar informações muito claras, expressas de forma literal em textos muito simples, com palavras do cotidiano doméstico - como tabelas, calendário, cartazes -, ler e escrever números relativos a questões do dia a dia - como preço, horário, telefone -, fazer operações matemáticas básicas e reconhecer sinais de pontuação. Já os alfabetizados elementares são capazes de selecionar uma ou mais unidades de informação, observando certas condições, em textos diversos, de extensão média, realizando pequenas inferências; estão em condições de realizar operações matemáticas simples com números na casa do milhar; podem comparar informações numéricas e textuais que envolvam situações cotidianas, em gráficos ou tabelas simples; podem reconhecer representações gráficas de grandezas. Os $24 \%$ de alfabetizados em nível intermediário interpretam informações expressas literalmente em textos variados e são capazes de realizar pequenas inferências; estão aptos a resolver problemas matemáticos envolvendo porcentagem e proporção e são capazes de resumir textos diversos, compreender argumentose confrontá-los com sua opinião ou com o senso comum. Diante desses dados, relativos a pessoas que estão inseridas no mercado do trabalho no Brasil, é possível se ter uma ideia do nível de letramento do todo da população brasileira. A capacidade de ler de forma crítica e analítica, estabelecendo uma relação texto-mundo, é condição escassa no cenário atual que, pleno de informações, exige do sujeito respostas eficientes e imediatas.

Se por um lado temos, historicamente, uma presença muito rarefeita da escola no tecido social brasileiro, situação que as recentes políticas educacionais, de forma ainda que incipiente, vinham tentando minimizar, por outro lado, e avolumada pela dificuldade de abrangência da educação, há a desmobilização da sociedade, o desconhecimento e o desinteresse pelos processos decisórios no País, conforme sinalizam, por exemplo, os números altíssimos de abstenções, votos nulos e brancos, nas eleições municipais de 2016, que superaram a votação dos candidatos eleitos no Rio de Janeiro, em Belo Horizonte e em Porto Alegre (ESPOSITO, LOURENÇO, 2016). Da mesma forma, a eleição presidencial de 2018, no segundo turno, apresentou um número de abstenções evotos nulos e brancos de quase 30\% (TSE, 2018). Este panorama das duas últimas eleições no Brasil aponta a condição de precariedade em dois dos princípios democráticos preconizados pela Constituição Brasileira: a educação e a participação.

\section{ESPECTADORES DESCOLONIZADOS, CIDADÃOS [E]LEITORES CONECTADOS}

A sociedade da informação, fruto do novo contexto tecnológico que substituiu a sociedade industrial, para se consolidar como novo modelo de organização social deverá superar problemas como a desigualdade de acesso à cultura, a condições de sobrevivência e à participação social e política. Isso significa que este novo paradigma deve, necessariamente, superar alguns desafios éticos para se consolidar. É nesse sentido que se torna de suma importância uma ação que corrija as desproporções, a fim de que seja possível uma desejável inclusão da sociedade como um todo neste novo mundo técnico-econômico-comunicacional. Se a desigualdade crônica alcançou este novo modelo, a realidade 
que se estabelece é a da desproporção do acesso à informação de qualidade e das capacidades de processá-la, apesar do barateamento dos equipamentos eletrônicos e de comunicação, repercutindo as velhas disparidades relativas a níveis educacionais e possibilidades de integração a consumo, conforto e saúde, situação que se desenha crítica nos países em desenvolvimento, pela sobreposição de processos excludentes (WERTHEIN, 2000).

Se o acesso à educação e à cultura não é equitativo, a condição de espectador de programas de televisão e o acesso à rede mundial de computadores praticamente se tornaram generalizados. Em 2017, 96,7\% da população possuía pelo menos uma televisão (IBGE, 2018); relativamente à conexão, a Pesquisa Nacional por Amostra de Domicílios Contínua TIC aponta que, em 2017, 74,9\% dos lares brasileiros estavam conectados à internet, sendo que $93,2 \%$ possuíam aparelhos celulares; o acesso à web via celular alcançou no mesmo ano 72,6\% das pessoas (IBGE, 2018), dado que agora certamente cresceu. Este é um aspecto a ser considerado, quando se pensa na profusão de textos e informações à qual tantos indivíduos são cotidianamente submetidos e nas suas condições de leitura e análise: o desafio de desatar as pontas do nó que acaba por entravar a inserção plena dos sujeitos nas várias tramas textuais que tecem o enredo ou os muitos enredos na nossa experiência contemporânea, monstruosamente interconectada à rede de informações e discursos que atravessam nossas existências, e aos quais devemos dar respostas rápidas e competentes, aprendendo a transitar entre eles, a tecer de muitos modos, se não quisermos ser devorados pela profusão de sentidos e significados que se espraiam através dos muitos canais - redes sociais, internet, TV, rádio.

Segundo Marilena Chaui, em Simulacro e poder: uma análise da mídia (2006), o modus operandi da comunicação de massa funciona de modo que o espectador não seja levado a questionar a informação que recebe, pois a lógica dos mass mediaé estimular sentimentos e emoções, e não pensamentos e análises. De fato, notícias, entrevistas e programas nunca se dirigem a quem participa para lhe perguntar "como avalia isto ou aquilo", "o que pensa disto ou daquilo", mas, em geral, "como sentiu tal coisa ou acontecimento". Assim, a informação fica minimizada, enquanto sobressaem sempre opiniões e sensações dos participantes do programa, e fica a cargo do apresentador expor a informação, explicá-la, interpretá-la. Os fatos são substituídos pelas análises que uma "personalidade autorizada" faz sobre eles. Assim, o público mantém-se na ilusão de estar sendo informado, pois passa a ter sentimentos e opiniões a respeito dos eventos; a exposição do fato "verdadeiro" é substituída por uma avaliação supostamente confiável. Este procedimento cria a noção de que os participantes do acontecimento (e os espectadores) são capazes apenas de sentir, enquanto os âncoras (e os especialistas) são responsáveis por pensar: são os únicos aptos a entender o que realmente aconteceu, e por isso são "formadores de opinião", ocupando, portanto, um lugar de saber (e de poder) na sociedade (CHAUI, 2006). Aqui não podemos deixar de fazer referência às redes sociais que, em sua velocidade e fluidez, vêm se tornando um espaço cada vez mais significativo para a comunicação e a formação de opinião. As plúrimas possibilidades dessas novas mídias permitem a veiculação de textos multimodais - imagens, sons, movimentos e escrita verbal - que ampliam enormemente o acesso a todo tipo de notícia, dados e comentários, em uma progressão rizomática e geométrica de proporções e velocidades incontroláveis, dificultando ainda mais o crivo crítico e as análises, já escassas nos meios tradicionais. Estabelece-se, assim, mais um nível de exclusão, em termos de capacidade de leitura: para além da educacional, mais ligada aos meios impressos, a digital, própria da comunicação de massa, da internet, das redes sociais. As múltiplas exclusões assinaladas dão conta de uma situação dramática, de um problema de dificuldade de letramento que se acumula e que entrava as reais possibilidades de cidadania e participação.

A desproporção de forças entre um Estado incapaz de promover uma educação de qualidade, que transforme o estudante em cidadão pela integração de saberes e pelas possibilidades de leitura de mundo, e a penetração dos meios de comunicação de massa e de tecnologias digitais parece levar à destruição da autonomia do pensamento, coisificando o ser humano e deixando-o ao sabor dos interesses corporativos. Paulo Freire preconizava em sua obra a educação das massas como ponto crucial para a nossa sociedade, pontuando a necessidade da escolha entre uma educação para alienação e domesticação ou para a liberdade. Dito de outro modo, a decisão que se apresenta é por um modelo educacional para o ser humano-objeto ou para o ser humano-sujeito. Na década de 1960, para Freire, o 
grande problema da sociedade era a configuração do ser humano, cotidianamente em relação com a indústria cultural que, segundo a ótica do educador pernambucano, aprisionava o sujeito, fazendo com que ele perdesse a capacidade de escolha e participação (FREIRE, 2013). Atualizando este quadro, mais demeio século depois, deve ser acrescentada a teia de informações que alcança e enreda o indivíduo por meio da internet e das networks sociais. Hoje a questão se tornou ainda mais complexa, inclusive diante das novas variáveis e em função das múltiplas exclusões apresentadas no parágrafo anterior: é fato que instrução e acesso à educação, como condições isoladas, nem sempre significam capacidade de interpretar o mundo e de se situar como sujeito. Da mesma forma, a ausência ou incipiência educacional também não representariam por si a impossibilidade de o indivíduo se compreender como sujeito e/ou atribuir sentido ao mundo. A saída desta encruzilhada poderia, entretanto, estar ligada à participação, baseada numa educação para a cidadania que, por sua vez, requer investimento maciço em programas de letramento amplos, direcionados e em conexão com os mais variados meios: impressos, televisivos e em rede.

Nesta empreitada, torna-se essencial a compreensão do letramento como possibilidade, mas não como causa efetiva, do desenvolvimento de condições cognitivas capazes de produzir transformação social, uma vez que a mudança estaria atrelada a "fatores concomitantes de ecologia, relações intersociais e respostas ideológicas internas e sócio-estruturais a estes fatores" (GRAFF, 1995, p.4, tradução minha). O letramento por si só não promove o avanço cognitivo, a empregabilidade e o desenvolvimento de uma capacidade discursiva. É preciso considerá-lo sempre em tensão com o contexto social e localizá-lo em estruturas de poder e ideologia, tendo-se em conta o pressuposto de que suas consequências e sucessos variam conforme a situação, de forma a não reproduzirmos a crença nos mitos do letramento (STREET, 2014), cujos fundamentos ainda permanecem presentes no quadro teórico que orienta programas e estudos sobre o tema. Nesse sentido, vislumbramos a complexidade da tarefa de desenvolver estratégias para programas que lidem com a variedade de necessidades letradas na sociedade contemporânea, no âmbito de um modelo educacional para a cidadania que envolva programas de multiletramentos, considerando os novos meios onde as práticas sociais de leitura e escrita estão a reclamar dos leitores habilidades cognitivas diferentes das tradicionais (STREET, 2014).

Os desafios propostos pelas configurações de uma ordem que, a partir das duas últimas décadas do século XX, vem rapidamente transformando o mundo tomam dimensões dramáticas nos países em desenvolvimento, que precisam, a despeito da não completude de vários processos de inclusão e democratização, se inserir neste movimento da pós-modernidade. $O$ arguto pensamento de Paulo Freire já alcançava esta problemática em meados dos anos 1960, identificando um momento de transição vivido por sociedades como a brasileira, passagem para um período marcado pela velocidade e flexibilidade, que estava exigindo dos sujeitos uma adaptação, representada pelo cada vez mais constante uso de capacidades intelectuais (FREIRE, 2013). O educador percebia um embate entre um passado não totalmente acabado e um futuro que se apressava em chegar. Esta transição é, necessariamente, um momento de escolha que deve estar baseada na liberdade conquistada pela consciência do instante, bem como na questão que se apresenta ao conhecimento, exigindo ação, atitude. O Brasil era analisado, assim, como sociedade em trânsito, com conflitos resultantes das contradições entre os valores do passado e os do futuro, passando da condição de sociedade fechada reflexa, marcada pelo papel alienado e alienante de suas elites alijadas da realidade do povo que, por sua vez, não tinha nenhum contato com as decisões, nenhum papel a desempenhar - à condição de sociedade aberta, na qual o direito à participação estaria consolidado. Vale dizer que as sociedades em trânsito representam um momento em que os temas da democracia, da participação, da cidadania, da liberdade já começam a assumir importância e conotação bastante diferenciadas em relação ao lugar que estes valores ocupam nas sociedades fechadas. Para uma sociedade aberta, de acordo com o pensador pernambucano, faz-se necessária a efetiva transformação da relevância assumida pelo conceito de cidadania, do próprio lugar do povo e da função que este desempenha nos destinos do organismo social. Por isso o momento da passagem é crucial, pois é o momento de transformação e, como tal, exige uma educação inclusiva, que desenvolva sujeitos críticos e ativos. No trânsito, os passos não são firmemente progressivos, são vacilantes, mas não implicam retrocesso. O importante é 
compreender que a transição se faz de forma dinâmica, comportando, portanto, avanços e recuos que devem ser percebidos como próprios do processo (FREIRE, 2013).

Com um intervalo de quase vinte anos, depois dessas reflexões de Paulo Freire, a Constituição Federal de 1988 acabou por consagrar como horizonte de expectativa uma sociedade aberta, em que o direito à participação estivesse ao alcance de todos. Não por acaso, esta sétima constituição da história do Brasil foi nomeada de "A Cidadã": resultava de um consenso social que, àquela altura, primava por um modelo de Estado Social e Democrático de Direito, resultante de uma concepção jurídica que percebia o direito como fonte de transformação e emancipação social. Nesse sentido, afirmamos a necessidade de participação e comunicação como procedimentos de construção das decisões jurídicas, tendo-se como elemento essencial a esta nova configuração a formação de redes de participação comunicativa, fator fundamental para as necessárias dinâmicas da vida social, complexa e pluralista (HABERMAS, apud BITTAR, 2014).

A questão aqui colocada é a da dificuldade de se implementarem na sociedade brasileira a participação e a cidadania no contexto pós-moderno de tantos desafios para as democracias no mundo. Está claro que o caminho é a adoção de procedimentos de inclusão e pluralidade, de forma que a política esteja acessível e em relação com as demandas sociais, sendo essencial a compreensão, por parte dos sujeitos envolvidos no processo, da relevância de determinadas questões cuja importância impacta o coletivo. A proposta de ação comunicativa é trabalhar e construir uma vontade política forte e autônoma em lugar do conhecido desinteresse. Esta transformação, no entanto, depende de como afrontamos os problemas decorrentes de uma sociedade consumista, caracterizada pelo isolamento social e por frágeis relações de identidades políticas, condições que constituem marcas das subjetividades contemporâneas. A razão para tamanha desmobilização e apatia participativa poderia estar na percepção da massa de que sua intervenção não se converteria em possibilidade real de influir nos processos decisórios ou transformar a ordem estabelecida. Na realidade, e considerando a histórica exclusão da população brasileira da gestão do País, o mais corriqueiro é a não compreensão do liame entre as escolhas políticas e as suas próprias vidas. Este alheamento conduz também à reflexão sobre um sensível desinteresse de muitos estudantes brasileiros em relação à escola, encontrado, sobretudo, em instituições educacionais frequentadas pelas camadas mais vulneráveis da população. $O$ questionamento que propomos é: em que medida um jovem oriundo de estratos mais pobres consegue vislumbrar o caráter transformador da educação, e como ela pode mudar a sua vida?

A dificuldade para se vislumbrar a participação e a cidadania como uma constante social parece também intimamente ligada a certos limites de liberdade, conforme expõe Eduardo Bittar (2014) em sua obra $O$ direito na pós-modernidade. Para o estudioso, as democracias apresentam alguns problemas que derivam do fato de em muitas organizações sociais os indivíduos ocuparem uma posição passiva, e suas liberdades se darem inteiramente dentro dos limites estabelecidos pelo sistema social. Nesse sentido, e se apoiando em Marcuse,Bittar explica que a liberdade se constitui como elemento de limitação e adaptação, que são, na análise do jurista, tendências repressivas e regressivas que acompanham as transformações da sociedade industrial para a tecnológica e que seguem também as mudanças no âmbito do trabalho, da mentalidade e da função política do povo, produzindo alguns entraves à democracia (MARCUSE, apud BITTAR, 2014). Em suma, a questão do individualismo das sociedades contemporâneas afigura-se como um obstáculo à democracia e resulta deste substrato que, entranhado no tecido social, apresenta a aceitação naturalizada de um determinado estado de coisas como única possibilidade, diante de um entendimento de que a participação seria incapaz de promover mudanças. Por tudo isso, o individualismo constitui-se em entrave à democracia, fortalecendo, ainda, $\mathrm{o}$ neoconservadorismo, o cinismo e o liberalismo.

Diante de tão forte obstáculo à democracia e à participação, aparece como alternativa possível pensar a esfera pública política como um espaço capaz de vincular a autonomia individual à autonomia coletiva, ambas as instâncias dotadas de poder comunicativo, o que significa que a autonomia social surge à medida que existe a autonomia do indivíduo. Assim, o espaço público configura-se como rede de comunicação que oferece à sociedade a oportunidade de conhecer e pensar sobre seus problemas, sua história, projetando soluções e esperanças para o futuro. Esta forma de democracia, assim considerada, resulta das reflexões acerca da Teoria da Ação Comunicativa, de 
Habermas, e está intimamente relacionada ao direito e à comunicação, sendo fundamentada em uma cultura participativa que fomente a criação de esfera pública que seja favorável à inclusão popular nas decisões que afetam, do ponto de vista prático, a economia, a política e a vida do cidadão. O requisito da participação que legitima o próprio exercício do poder, contudo, demanda qualidade de discussão, o que implica também a qualidade do processo democrático (HABERMAS apud BITTAR, 2014). É nesse sentido que a educação surge como pedra fundamental para este agir comunicativo, pois a participação e o engajamento exigem dos atores envolvidos condições de letramento, leitura crítica dos fatos e das questões relevantes para a sociedade, ou seja, inclusão discursiva. Assim, uma educação para a cidadania, não apenas forjada para atender à necessidade de mão de obra para o mercado, mas formadora de uma consciência das responsabilidades perante a comunidade, é fundamental para a efetivação das trocas simbólicas nos processos sociais. A educação para a liberdade produz a necessária emancipação, proporcionando a autonomia do sujeito, tornado artífice da transformação social, da interação, no convívio com as diferenças e com a pluralidade de ideias (FREIRE, 2013).

Neste contexto, focalizamos a necessidade de compreender o posicionamento central da capacidade de leitura, da competência em construir relações entre os mais variados textos que se apresentam ao indivíduo na veloz sucessão de fatos, conceitos, histórias que se disseminam por toda parte, através das tecnologias da comunicação e da informação que comandam o mundo contemporâneo. Eficiência e velocidade são pré-requisitos para lidar com esta trama que se espraia em redes, para juntar os fios das muitas histórias veiculadas todos os dias: tecer o tempo todo e em todos os modos é essencial ao sujeito pós-moderno que presencia, em alta rotação, uma profusão de narrativas que atravessa o cotidiano pós-industrial. Tal conjuntura já estava mais ou menos delineada no ano de 1985, quando Italo Calvino elaborou as condições que "o próximo milênio" estava a exigir da literatura e da narrativa (CALVINO, 2003). Dentre os seis aspectos literários apontados pelo autor, todos igualmente importantes para se compreender a comunicação a ser estabelecida com os leitores do século vindouro, abordamos aqui, mais especificamente, a velocidade e a exatidão. $O$ fundamento da rapidez, no segundo ensaio do volume, é explicado em termos de velocidade mental e descrito como propriedade de adaptação e agilidade de pensamento, para que se evite o choque entre velocidade e lentidão, descrito no ensaio $A$ mala postal, escrito pelo inglês Thomas De Quincey em 1849, quando se considerava que estava surgindo uma inédita velocidade nos transportes e nas informações. Esse ensaio é apresentado por Calvino para explicar os efeitos da não sincronia da literatura com o horizonte tecnológico que ele vislumbrava no futuro próximo; assim, ele utiliza a narrativa de De Quincey do acidente trágico em uma estrada entre uma diligência moderníssima, que avança a 13 milhas por hora, e que vai, inexoravelmente, em direção a uma caleche de vime que trafega tranquilamente à velocidade de uma milha por hora. Ainda para explicar a importância da rapidez, Calvino expõe a metáfora do cavalo, usada por Galileu Galilei para exemplificar a velocidade da mente nos discursos, citando-o textualmente - "discorrer é como correr" (CALVINO, 2003, p. 56) - para mostrar a necessidade de agilidade de raciocínio e economia de argumentos. Assim, Calvino descreve as duas faces do modo de pensar de Galileu, como paradigma competente de raciocínio: uma combinação de rigor mais lento e metódico com uma rapidez discursiva e espírito imaginativo, somatório que denota também a exatidão. Numa configuração em que a comunicação se pauta pela velocidade, a exatidão - uso cuidadoso da linguagem, capacidade de traduzir matizes e sutilezas de um pensamento assume importância fundamental, como vetor das respostas imediatas requeridas neste processo de trocas, na nossa era de comunicação generalizada. Parece lógico pensar que as mesmas características que deveriam estar presentes nas narrativas do século XXI - o futuro que Calvino, morto em 1985, não chegaria a ver - sejam também indispensáveis ao leitor da era globalizada do nosso tempo presente, como resultantes de uma educação democrática, inclusiva e cidadã, em que as práticas sociais da leitura e da escrita tenham lugar central na formação do estudante e sejam aplicadas em liberdade, de forma crítica, a partir de um conhecimento construído de forma dialogal e concretizado em produções orais e escritas.

A prática social da leitura e da escrita afirma-se como construção identitária e de cidadania, e parte de uma perspectiva que contempla o letramento - afastando-se, como já se explicou, da ideia de mera habilitação para decifração de código, muito vinculada ao desenvolvimento de competências 
individuais - para forjar uma outra habilidade que se concretiza através da leitura e da escrita como exercício social e em conexão com o contexto. Nessa visão, não interessa o enfoque no qual prevalecem apenas os mecanismos de adaptação dos educandos às necessidades sociais de leitura e escrita, como instrumento de inserção na cultura de massa ou de formação de mão de obra para o trabalho, sempre dentro dos moldes pré-estabelecidos por uma ordem de dominação, de adestramento dos corpos e das mentes, dirigida e programada por paradigmas de ordem socioeconômica.

Tratar do letramento envolve a noção de um processo relacionado à apropriação da leitura e da escrita, como método ativo de produção de sentidos, entendido enquanto mecanismo que abarca conhecimento, interação social e relações de poder derivadas do uso da escrita e dos mais diversos meios de comunicação. Dessa forma, o letramento apresenta-se como proposta contra-hegemônica aos "discursos competentes" circulantes em todos os meios de comunicação, que decorrem da histórica perspectiva de divisão social de funções, padrão de poder que coloniza mentes, saberes e corpos e se apoia numa hierarquia que estabelece quem formula ideias e, portanto, tem discurso competente, apto a interpretar/ler o mundo, em contraposição ao discurso - ou ao silêncio - daqueles que apenas cumprem tarefas, oprimidos, meros receptores de mensagens, conceitos, narrativas, visões de mundo.

A educação- livre, crítica e integrada a todos os espaços da convivência social - parece ser o fator de equilíbrio e certamente será o patamar seguro onde o indivíduo fincará seus pés e tomará impulso para conquistar as linguagens do mundo da tecnologia e da informação generalizada. Somente uma educação transformadora poderá fornecer meios ao sujeito, deixando-o apto ao embate que se dará nos movediços terrenos textuais dos diversos meios de comunicação, desafiando-o a ler com competência e velocidade as informações que lhe são lançadas. $\mathrm{O}$ emaranhado de discursos e narrativas prontas e formatadas, como belíssimos e saborosos pratos feitos, seduzem o espectador, internauta, leitor de jornais ou revistas; mas é preciso entrar neste jogo com astúcia, mediante a assimilação do meio, o conhecimento das instâncias e lugares de fala de cada personagem envolvido na cena comunicativa. Antes de se encantar com as sereias, é preciso lográ-las. E, aqui, mais uma vez recorre-se ao pensamento de Adorno e Horkheimer (1985b, p.47-70), mas revertendo-o. Trata-se de uma analogia a partir do ensaio Ulisses on o mito do esclarecimento, contido em $A$ dialética do esclarecimento. Os autores analisam o herói da Odisseia, Ulisses, como o protótipo do indivíduo burguês. A astúcia do personagem de Homero, para sair vencedor nas aventuras em que é lançado, na sua longa viagem de retorno a Ítaca, baseia-se no logro calculado, não diferente da forma como, segundo os autores, operará a racionalidade burguesa, muitos séculos depois, na figura do explorador europeu civilizado. Ulisses sai vencedor no episódio em que deve atravessar de barco o perigoso estreito de Cila e Caríbdis, onde os navegantes caem ao mar e morrem ao ouvir o canto das sereias, por empregar a astúcia de pedir que seus companheiros tampem os ouvidos com cera para não ouvir as criaturas sedutoras e assim continuem o trabalho de remar; ao mesmo tempo, Ulisses pede que eles o amarrem ao mastro antes da passagem pelas sereias, para que possa ouvi-las sem ser arrebatado. Ulisses, com o artifício de se deixar amarrar, encontra um modo de passar pela prova e, em segurança, ouvir o canto das sereias; a astúcia consiste em respeitar as convenções, mas lograr o oponente na medida em que encontra uma lacuna, uma brecha no pacto celebrado entre as partes. Segundo os autores, este método remete a um modelo econômico capitalista. "O desamparo de Ulisses diante da fúria do mar já soa como a legitimação do viajante que se enriquece às custas do nativo. Foi isso que a teoria econômica burguesa fixou posteriormente no conceito do risco: a possibilidade da ruína é a justificativa moral do lucro" (ADORNO, HORKHEIMER, 1985b, p. 58-59).

O letramento e a educação para a cidadania afigurar-se-iam nos termos da astúcia de Ulisses, retirando dela, todavia, a carga de uma prefiguração da razão colonial burguesa, para concebêla como alternativa contra-hegemônica, a criar espaços de resistência e luta. A astúcia, nesse sentido, incidiria como um modo de o leitor, cidadão, assimilar o meio, devolvendo o que lhe é próprio, ou seja, lendo o contexto como sujeito da ação, sabedor e conhecedor da natureza e dos processos econômicos, sociais e culturais inerentes à condição pós-moderna. É possível ouvir o canto das sereias, mas não se pode estar diante dele como cegos, nem menosprezar o seu apelo de sedução. Não se pode ignorar a globalização ou dela fugir, pois é um processo irreversível: o desafio está posto, o caminho está traçado, resta percorrê-lo, encontrar um modo de cumprir o contrato, mas explorando as lacunas, 
os espaços vazios no sistema, e assim vencer o jogo desmedido, tal como Ulisses que, sabedor da força da canção, se deixa amarrar ao mastro para ouvi-la, sem, contudo, ser arrebatado, dominado, morto, enquanto os seus companheiros, desamarrados, mas com os ouvidos tampados com cera, conduzem o barco a um ponto seguro.

\section{CONSIDERAÇÕES FINAIS}

Trabalhamos com o paradigma ideológico de letramento, o que nos leva a contextualizá-lo social e culturalmente e nas análises das estruturas de poder em que se insere, o que desenvolvemos quando abordamos não só a força do estruturalismo na formação dos professores de língua portuguesa- um modelo que, em muitos casos, negligencia a importância do uso social da língua -, mas também a nossa história, do passado colonial à recente democratização, que representou um novo pacto social, consolidado numa lei fundamental que prima pela cidadania e pela participação, tendo como base uma concepção plural do direito e o respeito à diversidade.Da mesma forma,essa contextualização se dá quando analisamos que as nossas políticas educacionais sempre se eximiram de visar a uma formação para a liberdade e para a autonomia do sujeito, oferecendo projetos que geralmente contemplam uma reprodução do conhecimento de per si, como um dado solto, descolado das estruturas de poder e da cultura. Esta educação é concebida como objeto neutro, apenas para formar mão de obra, o que implicaria conformar indivíduos que recebem saberes e os situam como isentos, repetindo este movimento com os textos, assimilados e consumidos, muitas vezes de forma acrítica, adestrados que foram para reproduzir em todas as esferas da vida a passividade cultivada por um modelo educacional autoritário e disciplinar, com conteúdos passados de forma fragmentada, mecânica, que não dialogam entre si, o que não estimula a análise e a reflexão como gestos constantes, performance que orientará sua leitura dos textos do mundo. Assim, as políticas educacionais que contemplam formas de letramento concebidas com base no modelo autônomo - cujo foco se concentra unicamente na capacidade cognitiva individual de usar a escrita, sem levar em consideração o contexto social - e encapsuladas, por sua vez, também em uma estrutura de poder estabelecida, não têm contribuído para promover a resistência e a criatividade necessárias para que os sujeitos possam lidar com os discursos hegemônicos, processá-los e devolvê-los como novas proposições, num tensionamento próprio do jogo democrático, só possível com a inclusão discursiva, ponto fundamental para a formação cidadã que concretiza a participação, elemento indispensável à qualidade da democracia. É preciso, portanto, superar este impasse se quisermos avançar e construir a tão almejada justiça social.

Letrar é dotar o estudante de conhecimentos, significados e práticas sociais que estão ligadas à democracia, com a finalidade de aperfeiçoá-la e fortalecê-la. Indispensável é também a apropriação de valores como igualdade, liberdade e solidariedade como pilares de um Estado de Direito. Dessa forma, o letramento afigura-se como possibilidadede equidade social, liberdade humana, forma de construção da autonomia e da emancipação dos sujeitos.

Educar com base em práticas sociais de leitura e escrita potencializa uma pedagogia da e para a democracia, constituindo-se como forma de se implementar a formação de sujeitos leitores do mundo, espectadores/comunicadores descolonizados e cidadãos, e para isso se faz necessário tornar as práticas de letramento centrais na política educacional brasileira, tanto para o ensino de língua portuguesa, como a partir da construção de uma profícua relação deste conceito com outras disciplinas do currículo da educação básica -tudo isso com o objetivo de se alcançar uma educação que seja dinâmica e integre conhecimentos, ao invés de fracioná-los em currículos que estrangulam um percurso formativo que poderia ser pleno e transformador. É preciso, portanto, assumir a necessidade de uma educação para a cidadania como função da escola, em detrimento de um ensino exclusivamente voltado para a preparação do trabalhador para o mercado.

Por fim, salientamos que este artigo é parte de uma reflexão mais ampla, um projeto de pesquisa in progress em torno da problemática da relação entre meios de comunicação e leitura. 
Objetiva-se, ao longo desta reflexão, em futuro próximo, apontar possibilidades concretas de ação na educação básica, para desenvolver projetos pedagógicos que visem à formação do cidadão, do sujeito leitor apto a construir seus discursos e a desenvolver uma leitura crítica do contexto em que vive. Dessa forma, identificamos o letramento como ponto de partida, fundamento para uma praxis educativa que atenda às necessidades de aprimoramento democrático, num contexto mundial de crise sempre mais evidente deste instrumento de equidade e justiça. Nesse sentido, num mundo assolado pela cultura do individualismo e do consumo - entraves à participação cidadã que legitima e dinamiza a democracia -, cabe ao letramento a tarefa de preparar indivíduos que, colocados diante da esfinge, precisam dar respostas rápidas e competentes ao desafio diário de uma sociedade de comunicação generalizada que, com seu excesso de informações, ameaça devorá-los.

\section{REFERÊNCIAS}

ADORNO, T. Televisão e formação. In ADORNO, T. Educação e emancipação. Traduzido por Wolfgang Leo Maar. São Paulo: Paz e Terra, 1995. p.75-96.

ADORNO, T., HORKHEIMER, M. A indústria cultural: o esclarecimento como mistificação das massas. In: ADORNO, T, HORKHEIMER, M.Dialética do esclarecimento. Traduzido por Guido Antonio de Almeida. Rio de Janeiro, Zahar, 1985a. p. 99-138.

ADORNO, T., HORKHEIMER, M.. Excurso I: Ulisses ou mito e esclarecimento. In: ADORNO, HORKHEIMER.Dialética do esclarecimento. Traduzido por Guido Antonio de Almeida. Rio de Janeiro, Zahar, 1985b. p. 47-70.

ARAÚJO, I. . Do signo ao discurso: introdução à filosofia da linguagem. São Paulo: Parábola editorial, 2004.

ARENDT, H. La crisi della cultura: nella società e nella politica. In: ARENDT, H. Tra passato e futuro. Traduzione di M. B. di L. Malagodi. Firenze: Vallecchi, 1970. p.215-245

BITTAR, E C. B. O direito na pós-modernidade. 3. ed. São Paulo: Atlas, 2014.

BRASIL. Constituição. Constituição da República Federativa do Brasil. Brasília, DF, 05 de outubro de 1988. Disponível em:

http://www.planalto.gov.br/ccivil 03/constituicao/constituicao.htm. Acesso em: 25 jun. 2020.

BRASIL.Emenda Constitucional no 25, de 15 de maio de 1985. Altera dispositivos da Constituição Federal e estabelece outras normas constitucionais de caráter transitório. Diário Oficial da União Seção 1 - 16/5/1985, Página 7313. Disponível em:

https://www2.camara.leg.br/legin/fed/emecon/1980-1987/emendaconstitucional-25-15-maio-1985364956-norma-pl.html. Acesso em: 25 jun. 2020.

BRASIL. Lei no 5.379, de 15 de dezembro de 1967. Provê sobre a alfabetização funcional e a educação continuada de adolescentes e adultos. Diário Oficial da União - Seção 1 - 19/12/1967, Página 12727. Disponível em: https://www2.camara.leg.br/legin/fed/lei/1960-1969/lei-5379-15-dezembro-1967359071-publicacaooriginal-1-pl.html. Acesso em: 25 jun. 2020.

CALVINO, I. Seis propostas para o próximo milênio. Traduzido por Ivo Barroso. São Paulo: Companhia das Letras, 2003.

CHAUI, M. Simulacro e poder: uma análise da mídia. São Paulo: Editora Fundação Perseu Abramo, 2006. 
CICCO, C.; GONZAGA, A. Teoria geral do estado e ciência política. 7.ed. São Paulo: Editora Revista dos Tribunais, 2016.

DANTAS, H. O caráter essencial da educação política e o desenvolvimento da educação política no Brasil. Cadernos Adenauer XI. Rio de Janeiro, n.03, p. 3-12, 2010. Disponível em: http://www.kas.de/wf/doc/kas 20865-1522-5-30.pdf?110126203825. Acesso em: 07 jul. 2017.

ESPOSITO, I.; LOURENÇO, I. Brancos, nulos e abstenções superam votos de eleitos no RIO, BH e Porto Alegre. Carta Capital. 30/10/2016. Disponível em:

https://www.cartacapital.com.br/politica/brancos-nulos-e-abstencoes-superam-votos-de-eleitos-norio-bh-e-porto-alegre. Acesso em: 16 jun. 2017.

FGV. CPDOC da Fundação Getúlio Vargas. Rio de Janeiro, 2009. Disponível em: http://www.fgv.br/cpdoc/acervo/dicionarios/verbete-tematico/movimento-brasileiro-dealfabetizacao-mobral. Acesso em: 14 jun. 2017.

FREIRE, P. Educação como prática de liberdade. 15. ed. Rio de Janeiro: Paz e Terra, 2013.

FREIRE, P. A importância do ato de ler. 51.ed. São Paulo: Cortez, 2011.

FREITAS, H.C.L. de . Formação de professores no Brasil: 10 anos de embate entre projetos de formação. Educ. Soc., Campinas,SP, v. 23, n. 80, p. 136-167, Set. 2002. Disponível em:http://www.scielo.br/scielo.php?script=sci arttext\&pid=S010173302002008000009\&lng=en\&nrm=iso. Acesso em: 29 jun. 2020.

GEERTZ, C. A interpretação das culturas. Tradução de Fanny Wrobel. Rio de Janeiro: Editora Guanabara Koogan, 1989.

GRAFF, H. J. The Labyrinths of Literacy: reflections of Literacy Past and Present. Pittsburgh: University of Pittsburgh Press, 1995. Disponívelem: [muse.jhu.edu/book/27086]. Acessoem: 25 jun. 2020 .

HOGGART, R. The Uses of Literacy: Aspects of working-class life with special reference to publications and entertainments. 9. ed. Harmondsworth, England: Penguin Books, 1973.

IBGE. Pesquisa Nacional por Amostra de Domicílios. Acesso à Internet e à televisão e posse de telefone móvel celular para uso pessoal 2017. Rio de Janeiro, 2018. Disponível em: https://biblioteca.ibge.gov.br/visualizacao/livros/liv101631 informativo.pdf. Acesso em: 04 abr. 2020 .

IBGE. Séries históricas e estatísticas. s/d. Disponível em:https://seriesestatisticas.ibge.gov.br/series.aspx?no $=4 \& o p=0 \& v \operatorname{codigo}=C D 101 \& \mathrm{t}=\mathrm{taxa}-$ analfabetismo-pessoas-15-anos-mais. Acesso em: 04 abr. 2020.

INEP, Instituto Nacional de Estudos e Pesquisas Educacionais Anísio Teixeira. Boletins e Resultados/Desempenho. Disponível em:http://sistemasprovabrasil.inep.gov.br/provaBrasilResultados/view/boletimDesempenho/boletim Desempenho.seam. Acesso em: 26 jun. 2020.

INSTITUTO PAULO MONTENEGRO/AÇÃO EDUCATIVA. Indicador de Alfabetismo Funcional - INAF BRASIL 2018. Resultados preliminares. São Paulo: Ação Educativa, 2018. 
Disponível em: https://drive.google.com/file/d/1ez6jrlrRRUm9JJ3MkwxEUfflijCTEI6/ view. Acesso em: 03 abr. 2020.

MATTELART, A., NEVEU, É. Introdução aos estudos culturais. Tradução de Marcos Marcionillo. São Paulo: Parábola Editorial, 2004.

MENDES, E. O conceito de língua em perspectiva histórica: reflexos no ensino e na formação de professores. In: LOBO, T. et alii. Linguística histórica, história das línguas e outras histórias. Salvador: EDUFBA, 2012. p.667-677.

OLIVEIRA, L. Coisas que todo professor de português precisa saber: a teoria na prática. São Paulo: Parábola Editorial, 2014.

PINTO, J.M. et alii. Um olhar sobre os indicadores de analfabetismo no Brasil. Revista Brasileira de Estudos Pedagógicos, Brasília, v. 81, n. 199, p. 511-524, 2000. Disponível em:

http://rbep.inep.gov.br/index.php/rbep/article/view/971. Acesso em: 18 abr. 2019.

PISA. 2018 Results. OECD, 2019. Disponível em:https://www.oecd.org/pisa/Combined_Executive_Summaries_PISA_2018.pdf. Acesso em: 26 jun. 2020.

QEdu. Aprendizado dos alunos. Brasil. 2020. Disponível em:

https://www.qedu.org.br/brasil/aprendizado. Acesso em: 26 jun. 2020.

ROJO, R. Letramento e capacidades de leitura para a cidadania. São Paulo: See: Coordenadoria de Estudos e Normas Pedagógicas - CenP, p. 853, 2004. Disponível em:http://files.saladeleituradera.webnode.com/200000194e3ca4e4c46/ROJO\%20CAPACIDADES\%20DE\%20LEITURA.pdf. Acesso em: 25 jun. 2020.

SILVA, R.V.M. e. Ensaios para uma sócio-história do português brasileiro. São Paulo: Parábola Editorial, 2004.

SOARES, M. Letramento e alfabetização: as muitas facetas. Revista Brasileira de Educação. Rio de Janeiro,n. 25, p. 5-17 $1^{\circ}$ sem. 2004. Disponível em: http://www.scielo.br/pdf/rbedu/n25/n25a01.pdf. Acesso em: 25 jun. 2017.

SOFÓCLES. Trilogia tebana: Édipo Rei, Édipo em Colono e Antígona. Tradução de Mário da Gama Cury. Rio de Janeiro: Zahar, 1990.

STREET, B. V. Letramentos sociais: abordagens do letramento no desenvolvimento, na etnografia e na educação. Tradução de Marcos Bagno. São Paulo: Parábola Editorial, 2014.

TSE. Eleições 2018: justiça eleitoral conclui totalização dos votos do segundo turno. Disponível em: http://www.tse.jus.br/imprensa/noticias-tse/2018/Outubro/eleicoes-2018-justica-eleitoral-concluitotalizacao-dos-votos-do-segundo-turno. Acesso em: 06 fev. 2019.

WERTHEIN, J. Sociedade da informação e seus desafios. Ci. Inf. Brasília: v. 29, n. 2, p. 71-77, maio/ago. 2000. Disponível em: http://www.scielo.br/pdf/ci/v29n2/a09v29n2.pdf. Acesso em: 18 abr. 2019.

WOLKMER, A.C.; LEITE, J.R. Os “novos" direitos no Brasil: natureza e perspectivas - uma visão básica das novas conflitualidades jurídicas. 2.ed. São Paulo: Saraiva 2012. 
Submetido: $08 / 05 / 2019$

Aprovado: 02/07/2020 